\title{
Investigating Factors Associated with Depressive Symptoms of Chronic Kidney Diseases in China with Type 2 Diabetes
}

\author{
Xu Wang, ${ }^{1,2}$ Biyu Shen, ${ }^{1}$ Xun Zhuang, ${ }^{3}$ Xueqin Wang, ${ }^{4}$ and Weiqun Weng ${ }^{1}$ \\ ${ }^{1}$ Department of Nursing, The Second Affiliated Hospital of Nantong University, Nantong, Jiangsu Province, China \\ ${ }^{2}$ School of Nursing, Nantong University, Nantong, Jiangsu Province, China \\ ${ }^{3}$ Department of Epidemiology, School of Public Health, Nantong University, Nantong, Jiangsu Province, China \\ ${ }^{4}$ Department of Endocrinology, The Second Affiliated Hospital of Nantong University, Nantong, Jiangsu Province, China
}

Correspondence should be addressed to Weiqun Weng; wengweiqun011@163.com

Received 22 November 2016; Revised 21 December 2016; Accepted 15 January 2017; Published 2 February 2017

Academic Editor: Tao Xing

Copyright (c) $2017 \mathrm{Xu}$ Wang et al. This is an open access article distributed under the Creative Commons Attribution License, which permits unrestricted use, distribution, and reproduction in any medium, provided the original work is properly cited.

\begin{abstract}
Aim. To assess the depressive symptoms status of chronic kidney diseases in Nantong, China, with type 2 diabetes and to identify factors associated with depressive symptoms. Methods. In this cross-sectional analytic study, 210 type 2 diabetic patients were recruited from the Second Affiliated Hospital of Nantong University. Depressive symptoms were assessed with the depression subscale of the Hospital Anxiety and Depression Scale (HAD-D). The quality of life was measured with the RAND 36-Item Health Survey (SF-36). And the independent risk factors of depressive symptoms were assessed by using a stepwise forward model of logistic regression analysis. Results. The mean age of the study subjects was 57.66 years (SD: 11.68 ). Approximately $21.4 \%$ of subjects reported depressive symptoms $(n=45)$. Forward stepwise logistic regression analysis showed that female gender $(P=0.010)$, hypertension $(P=0.022)$, Stage IV $(P=0.003)$, and Stage V $(P<0.001)$ were significant risk factors for depressive symptoms. The quality of life of individuals with HAD-D score $<11$ was significantly better compared with individuals with HAD-D score 211. Conclusions. These results indicate that clinicians should be aware that female patients with chronic kidney diseases with T2DM in their late stage with hypertension are at a marked increased risk of depressive symptoms. Providing optimal care for the psychological health of this population is vital.
\end{abstract}

\section{Introduction}

In China, high rates of unhealthy diets, physical inactivity, and obesity have led to an increase in the prevalence of type 2 diabetes mellitus (T2DM). Over 100 million Chinese people currently suffer from T2DM. T2DM is a chronic disease that in the long-term increases the microvascular degenerative complication of chronic kidney disease (CKD), which is a leading cause of end-stage renal disease (ESRD) [1]. ESRD requires either dialysis or transplantation, which is associated with cumulative hospital days and number of hospitalizations, contributing to excessive Medicare costs $[2,3]$. CKD affects $20 \%$ to $40 \%$ of those who develop diabetes [4]. As the prevalence of T2DM in this country is increasing, the rate of CKD will also rise rapidly.

Depression is the third most important cause of disability in the world [5]. And having T2DM increases the risk of subsequent development or recurrence of depression. As an unwanted cotraveler of T2DM, depression can impinge on self-management ability and hinder patients adherence to treatment regime [6]. Furthermore, available studies have suggested that the presence of comorbid depression with diabetes is associated with poorer self-reported health status and higher adverse outcomes, including incident ESRD and mortality [7-13].

According to other documents, the prevalence of depression is observed in approximately $20 \%$ of patients with T2DM $[14,15]$. Considering the high prevalence of CKD in patients with diabetes and that depression is rather common in patients with T2DM, the factors associated with depression effect on CKD in T2DM are a growing concern.

To our knowledge, the associated factors with depression were younger age, female gender, socioeconomic status, presence of cardiovascular disease, and health status $[16,17]$. 
Furthermore, depression is associated with microalbuminuria in diabetes related CKD [18]. And low eGFR was regarded as a risk factor of depression in nondiabetic CKD $[19,20]$.

However, the factors associated with depressive symptoms among CKD in type 2 diabetic patients have not been examined in previous studies. Therefore we were specifically interested in the relationship between demographic, clinical variables, and depressive symptoms in CKD patients with T2DM.

The aim of this study was to assess the associations between depressive symptoms and kidney disease in an inpatient type 2 diabetic cohort and to learn about the warning signs of mood symptoms in these patients to provide early diagnosis and treatment.

\section{Methods}

2.1. Study Population and Recruitment. From October 2015 to April 2016, an observational cross-sectional study was conducted among the T2DM patients with CKD from the Second Affiliated Hospital of Nantong University. An eligible person fulfilled the 1999 World Health Organization (WHO) criteria for the diagnostic of T2DM or a hospital discharge diagnosis of T2DM. When abnormal estimated glomerular filtration rate (eGFR) or urinary albumin excretion rate (UAER) was presented in three months, T2DM patients would be categorized as having CKD. The severity of CKD in T2DM was categorized into five stages according to NKF-KDOQI Guidelines $[21,22]$ and the staging standard of CKD in type 1 diabetes [23]. Stage I: UAER < $10 \mu \mathrm{g} / \mathrm{min}$ and eGFR increased obviously, kidney size increased; Stage II: UAER $<20 \mu \mathrm{g} / \mathrm{min}$ or increased intermittently (such as exercise, stress state), eGFR increased slightly; Stage III: UAER 20 200 $\mu \mathrm{g} / \mathrm{min}$ (last for 3 months), eGFR is normal or above normal; Stage IV: UAER > $200 \mu \mathrm{g} / \mathrm{min}$, eGFR decreased; Stage V: end-stage renal failure, eGFR $<10 \mathrm{ml} / \mathrm{min}$. eGFR was estimated from modified MDRD equations---c-aGFR4 [24-26]. Cases were excluded on the basis of the following criteria: (1) age $<18$ or $>80$ years at the time of interview; (2) pregnant and lactating women; (3) hearing and cognitive impairment; (4) any unstable medical illness or mental disease; and (5) those who did not complete the questionnaire. Finally, 210 patients were eligible for investigation and entered the study.

In compliance with the Helsinki declaration, all subjects were told about the concept of the study and signed an informed consent prior to commencement of the study. Approval to conduct this study was obtained from the Ethics Committee of the Second Affiliated Hospital of Nantong University.

2.2. Instruments. Two scales, the Hospital Anxiety and Depression Scale (HAD) and the RAND 36-Item Health Survey (SF-36), were used to evaluate depressive symptoms and quality of life (QOL). The HAD [27], a reliable and valid selfreport rating scale [28], includes 7 items for anxiety (HAD-A) and 7 for depression (HAD-D). The total score is the sum of the 14 items with a four-point scale on each item (range $0-3$ ). For each subscale, the score is the sum of the respective seven items (ranging from 0 to 21). We defined the scores of HAD-D greater than 11 as depressive symptoms.

QOL were assessed with the SF-36, comprising 36 items organized into 8 scales: physical functioning (PF) (10 items), role physical (RP) (4 items), body pain (BP) (2 items), general health (GH) (5 items), energy/fatigue (VT) (4 items), social functioning (SF) (2 items), role emotional (RE) (3 items), and mental health ( $\mathrm{MH})$ (5 items). In addition to the above 8 aspects, SF-36 also contains another health indicator: reported health transition (HT) (1 item), used to evaluate the health status of the overall change in the past year. A Chinese version of the SF-36 scale has been validated by Wang et al. [29].

Each participant underwent an in-person interview of demographic data (age, gender, income, level of education, health coverage, etc.), diabetes characteristics (duration of diabetes, insulin therapy), and self-care behavior (clinic visit, blood glucose monitoring). Detailed clinical parameters (hypertension, HbAlc, plasma creatinine, and albuminuria) were abstracted from electronic medical record system.

2.3. Statistical Analysis. Statistical analyses were performed with SSPS 21.0. Descriptive statistics were calculated for all variables measured. Data were reported as mean (standard deviation [SD]) or median (interquartile range, IQR) or percentages. Significant differences were determined by using independent $t$-tests (continuous variables with normal distribution), Chi-Square tests (categorical variables), and MannWhitney tests (continuous variables with skewed distribution). A stepwise forward model of logistic regression was used to determine independent factors of depressive symptoms with odds ratios (ORs) and the corresponding 95\% CIs. Statistical significance was set at $P<0.05$ (two tailed).

\section{Results}

A total of 223 patients were invited to participate. Thirteen (5.8\%) were excluded because of incomplete data. Among the 210 total subjects, 45 (21.4\%) patients with T2DM had symptoms of depression. In Tables 1(a) and 1(b), for HAD-D scores $\geq 11$ patients, significant associations were found with female gender $(P=0.006)$, yearly income $(P=0.016)$, clinic visit frequency $(P=0.018)$, blood glucose monitoring frequency $(P=0.019)$, and duration of diabetes $(P=0.035)$. The HAD-D scores $\geq 11$ were higher in T2DM complicated with hypertension $(27.8 \%)$ compared with T2DM without hypertension $(13.7 \%)\left(\chi^{2}=6.18 ; P=0.013\right)$. The rates of depressive symptoms among patients in Stage IV and $\mathrm{V}$ were higher than patients in I-III $\left(\chi^{2}=23.28 ; P<0.001\right)$. About forty percent of the patients who reported depressive symptoms were found with low eGFR $\left(\chi^{2}=15.42 ; P<0.001\right)$ and macroalbuminuria $\left(\chi^{2}=17.49 ; P<0.001\right)$. However, there were no significant differences in depressive symptoms by age $(P=$ $0.533)$, employment status $(P=0.290)$, education $(P=$ $0.150)$, marital status $(P=0.093)$, insurance $(P=0.117)$, insulin use $(P=0.334)$, or $\mathrm{HbAlc}(P=0.921)$. 
TABLE 1: (a) Comparison of demographic factors of T2DM-related CKD patients by depressive symptoms status. (b) Comparison of clinical factors of T2DM-related CKD patients by depressive symptoms status.

(a)

\begin{tabular}{|c|c|c|c|c|c|}
\hline \multirow[b]{2}{*}{ Variables } & \multirow[b]{2}{*}{ Overall sample } & \multicolumn{2}{|c|}{ Depression status } & \multirow[b]{2}{*}{$\chi^{2} / z$} & \multirow[b]{2}{*}{$P$ value } \\
\hline & & $\begin{array}{c}\text { HAD-D score } \\
<11\end{array}$ & $\begin{array}{c}\text { HAD-D score } \\
\geq 11\end{array}$ & & \\
\hline Total, $n(\%)$ & 210 & $165(78.6)$ & $45(21.4)$ & & \\
\hline Gender, $n(\%)$ & & & & 7.507 & 0.006 \\
\hline Male & $108(51.4)$ & $93(86.1)$ & $15(13.9)$ & & \\
\hline Female & $102(45.1)$ & $72(70.6)$ & $30(29.4)$ & & \\
\hline Age (year), mean (SD) & $57.66(11.68)$ & $57.39(11.57)$ & $58.62(12.14)$ & $-0.624^{*}$ & 0.533 \\
\hline Employment status, $n(\%)$ & & & & 1.118 & 0.290 \\
\hline Working & $102(48.6)$ & $77(75.5)$ & $25(24.5)$ & & \\
\hline Not working & $108(51.4)$ & $88(81.5)$ & $20(18.5)$ & & \\
\hline Education, $n(\%)$ & & & & 3.791 & 0.150 \\
\hline Primary or below ( $0-6$ years) & $65(31.0)$ & $46(76.7)$ & $19(29.2)$ & & \\
\hline Secondary (7-13 years) & $122(58.1)$ & $99(79.2)$ & $23(18.9)$ & & \\
\hline Tertiary (>13 years) & $23(11.0)$ & $20(80.0)$ & $3(13.0)$ & & \\
\hline Marital status (married), $n(\%)$ & $189(90.0)$ & $152(80.4)$ & $37(19.6)$ & 2.828 & 0.093 \\
\hline Yearly income (RMB), $n(\%)$ & & & & 8.229 & 0.016 \\
\hline$<15000$ & $42(20.0)$ & $28(66.7)$ & $14(33.3)$ & & \\
\hline $15000 \sim 33000$ & $75(35.7)$ & $56(74.7)$ & $19(25.3)$ & & \\
\hline$>33000$ & $93(44.3)$ & $81(87.1)$ & $12(12.9)$ & & \\
\hline Insurance, $n(\%)$ & & & & 2.452 & 0.117 \\
\hline Rural medicare cooperative & $64(30.5)$ & $46(71.9)$ & $18(28.1)$ & & \\
\hline Medical insurance & $146(69.5)$ & $119(81.5)$ & 27 (18.5) & & \\
\hline
\end{tabular}

Bold values indicate significant results $(P<0.05)$.

${ }^{*}$ Independent $t$-tests.

(b)

\begin{tabular}{|c|c|c|c|c|c|}
\hline \multirow[b]{2}{*}{ Variables } & \multirow[b]{2}{*}{ Overall sample } & \multicolumn{2}{|c|}{ Depression Status } & \multirow[b]{2}{*}{$\chi^{2} / z$} & \multirow[b]{2}{*}{$P$ value } \\
\hline & & $\begin{array}{l}\text { HAD-D score } \\
<11\end{array}$ & $\begin{array}{l}\text { HAD-D score } \\
\quad \geq 11\end{array}$ & & \\
\hline $\begin{array}{l}\text { clinic visit frequency } \\
\text { (times/year), median (IQR) }\end{array}$ & $0.5(1.0)$ & $0.0(1.0)$ & $1.00(2.0)$ & -2.356 & 0.018 \\
\hline $\begin{array}{l}\text { blood glucose testing } \\
\text { (times/month), median (IQR) }\end{array}$ & $1.0(4.0)$ & $1.0(4.0)$ & $2.0(3.0)$ & -2.336 & 0.019 \\
\hline $\begin{array}{l}\text { Duration of diabetes (years), } \\
\text { median (IQR) }\end{array}$ & $7.0(12.0)$ & $6.0(12.92)$ & $8.0(10.5)$ & $-2.111^{*}$ & 0.035 \\
\hline Insulin use (yes), $n(\%)$ & $116(55.2)$ & $94(81.0)$ & $22(19.0)$ & 0.934 & 0.334 \\
\hline Hypertension (yes), $n$ (\%) & $115(54.8)$ & $83(72.2)$ & $32(27.8)$ & 6.180 & 0.013 \\
\hline HbAlc & & & & 0.010 & 0.921 \\
\hline$\leq 9$ & $78(37.1)$ & $61(78.2)$ & $17(21.8)$ & & \\
\hline$>9$ & $132(62.9)$ & $104(78.8)$ & $28(21.2)$ & & \\
\hline $\mathrm{eGFR}\left(\mathrm{mL} / \mathrm{min} / 1.73 \mathrm{~m}^{2}\right), n(\%)$ & & & & 15.420 & $<0.001$ \\
\hline$\geq 90$ & $75(35.7)$ & $68(90.7)$ & $7(9.3)$ & & \\
\hline $60-89$ & $105(50.0)$ & $80(76.2)$ & $25(23.8)$ & & \\
\hline$<60$ & $30(14.3)$ & $17(56.7)$ & $13(43.3)$ & & \\
\hline Albuminuria (mg/L), $n(\%)$ & & & & 17.485 & $<0.001$ \\
\hline Normal Albuminuria $(<20)$ & $109(51.9)$ & $96(88.1)$ & $13(11.9)$ & & \\
\hline Microalbuminuria (20 200) & $59(28.1)$ & $45(76.3)$ & $14(23.7)$ & & \\
\hline Macroalbuminuria $(>200)$ & $42(20.0)$ & $24(57.1)$ & $18(42.9)$ & & \\
\hline
\end{tabular}


(b) Continued.

\begin{tabular}{|c|c|c|c|c|c|}
\hline \multirow[b]{2}{*}{ Variables } & \multirow[b]{2}{*}{ Overall sample } & \multicolumn{2}{|c|}{ Depression Status } & \multirow[b]{2}{*}{$\chi^{2} / z$} & \multirow[b]{2}{*}{$P$ value } \\
\hline & & $\begin{array}{c}\text { HAD-D score } \\
<11\end{array}$ & $\begin{array}{c}\text { HAD-D score } \\
\geq 11\end{array}$ & & \\
\hline Severity of DKD, $n(\%)$ & & & & 23.283 & $<0.001$ \\
\hline Stage I & $74(35.2)$ & $68(91.9)$ & $6(8.1)$ & & \\
\hline Stage II & $41(19.5)$ & $31(75.6)$ & $10(24.4)$ & & \\
\hline Stage III & $55(26.2)$ & $44(80.0)$ & $11(20.0)$ & & \\
\hline Stage IV & $24(11.4)$ & $15(62.5)$ & $9(37.5)$ & & \\
\hline Stage V & $16(7.6)$ & $7(43.8)$ & $9(56.3)$ & & \\
\hline
\end{tabular}

Bold values indicate significant results $(P<0.05)$.

${ }^{*}$ Mann-Whitney test.

TABLE 2: Logistic regression model of T2DM-related CKD patients on depressive symptoms.

\begin{tabular}{|c|c|c|c|c|c|c|c|}
\hline \multirow{2}{*}{ Variables } & \multirow{2}{*}{$B$} & \multirow{2}{*}{ SE } & \multirow{2}{*}{ Wald } & \multirow{2}{*}{ OR } & \multicolumn{2}{|c|}{$\exp (B) 95 \% \mathrm{CI}$} & \multirow{2}{*}{$P$ value } \\
\hline & & & & & Lower bound & Upper bound & \\
\hline \multicolumn{8}{|l|}{ Hypertension } \\
\hline Without hypertension & - & - & - & REF & - & - & - \\
\hline With hypertension & 0.902 & 0.395 & 5.208 & 2.465 & 1.136 & 5.350 & 0.022 \\
\hline Severity of T2DM-related CKD & & & 16.779 & & & & 0.002 \\
\hline Stage I & - & - & - & REF & - & - & - \\
\hline Stage II & 1.056 & 0.576 & 3.357 & 2.875 & 0.929 & 8.899 & 0.067 \\
\hline Stage III & 0.837 & 0.558 & 2.252 & 2.309 & 0.774 & 6.886 & 0.133 \\
\hline Stage IV & 1.877 & 0.622 & 9.095 & 6.533 & 1.929 & 22.122 & 0.003 \\
\hline Stage V & 2.464 & 0.682 & 13.056 & 11.755 & 3.088 & 44.744 & 0.000 \\
\hline \multicolumn{8}{|l|}{ Gender } \\
\hline Female & 0.993 & 0.387 & 6.586 & 2.699 & 1.264 & 5.760 & 0.010 \\
\hline Male & - & - & - & REF & - & - & - \\
\hline
\end{tabular}

REF: reference group.

Bold values indicate significant results $(P<0.05)$.

Forward stepwise logistic regression analysis was used to identify a model to predict T2DM-related CKD patient who would have depressive symptoms. The results showed that variables of female gender, severity of T2DM-related CKD, and complicated hypertension were significant risk factors for depressive symptoms (Table 2). This model had a good fit under the Hosmer-Lemeshow goodness-of-fit test $\left(R^{2}=\right.$ $\left.0.233, \chi^{2}=7.568, P=0.477\right)$, and accuracy of the model was $78.5 \%$.

T2DM patients with hypertension were 2.5 times more likely to experience depressive symptoms than T2DM patients without hypertension $(P=0.022)$. The likelihood of depressive symptoms in Stage IV was 6.5 times more than that in stage I, and Stage V was 11.8 times. Female patients were 2.6 times more likely to report depressive symptoms than male patients.

Finally, the subjects were divided into two groups according to the HAD-D score. An analysis showed that all the dimension scores of SF-36 in individuals with HAD-D score $<11$ were significantly higher compared with individuals with HAD-D score $\geq 11(P<0.05)$. The results are shown in Table 3.

\section{Discussion}

We found that almost $21.4 \%$ of subjects had depressive symptoms (HAD-D score $\geq 11$ ). And the depressive symptoms were negatively associated with patients' quality of life. Depressive symptoms are becoming a serious problem.

We also found the differences between T2DM patients with and without depressive symptoms were yearly income, clinic visit frequency, blood glucose testing frequency, diabetic duration, eGFR, and albuminuria by univariate analysis. The lower compliance to the self-care measures of clinic visit and blood glucose testing will lead to a poor glycemic control which can contribute to the occurrence of diabetic complications [30, 31]. Besides, an increased duration of T2DM contributes significantly to an increase in the risk of diabetic complications. Low eGFR and macroalbuminuria revealed severe renal impairment which could require dialysis or kidney transplantation. These adverse consequences will lead to the increased economic burden of healthcare costs for lower income group. Due to economic instability and increased healthcare expenditures for complications and adherence to treatment, these patients are more susceptible to experiencing psychological diseases [32]. 
TABLE 3: Comparison between the HAD-D score $\geq 11$ group and HAD-D score $<11$ group in SF-36 domain score.

\begin{tabular}{|c|c|c|c|c|c|}
\hline $\begin{array}{l}\text { QOL assessments } \\
\text { (SF-36 domains), } \\
\text { mean (SD) }\end{array}$ & Overall sample & HAD-D score $<11$ & HAD-D score $\geq 11$ & $Z$ & $P$ value \\
\hline $\mathrm{PF}$ & $85.52(23.62)$ & 88.86 (19.83) & $59.55(33.45)$ & -4.685 & $<0.001$ \\
\hline $\mathrm{RP}$ & $62.82(44.42)$ & $67.40(42.71)$ & $27.27(42.19)$ & -3.649 & $<0.001$ \\
\hline $\mathrm{BP}$ & $85.81(22.63)$ & $87.30(22.19)$ & $74.27(23.25)$ & -2.929 & 0.003 \\
\hline $\mathrm{GH}$ & $57.28(24.33)$ & $60.47(23.23)$ & $32.50(17.85)$ & -4.919 & $<0.001$ \\
\hline VT & $65.03(19.01)$ & $66.96(18.36)$ & $50.00(17.53)$ & -3.933 & $<0.001$ \\
\hline SF & $91.26(18.76)$ & $94.23(14.17)$ & $68.18(31.04)$ & -5.033 & $<0.001$ \\
\hline $\mathrm{RE}$ & $89.12(30.66)$ & $93.18(25.29)$ & $57.58(47.34)$ & -4.969 & $<0.001$ \\
\hline $\mathrm{MH}$ & $82.32(11.72)$ & $84.40(8.38)$ & $66.18(19.47)$ & -4.714 & $<0.001$ \\
\hline $\mathrm{HT}$ & $39.38(18.33)$ & $40.94(18.14)$ & $27.27(15.25)$ & -3.185 & 0.001 \\
\hline PCS & $72.82(21.70)$ & 75.96 (19.83) & $48.40(20.47)$ & -5.056 & $<0.001$ \\
\hline MCS & 81.90 (15.28) & 84.66 (11.77) & $60.48(21.71)$ & -5.994 & $<0.001$ \\
\hline Total score & $71.54(13.20)$ & $73.93(11.00)$ & $53.01(14.36)$ & -5.790 & $<0.001$ \\
\hline
\end{tabular}

Bold values indicate significant results $(P<0.05)$.

PCS: the physical component summary.

MCS: the mental component summary.

However, age, being unmarried, low monthly income, low educational level, unemployment, and HbAlc associated with depressive symptoms occurrence in T2DM patients have been proved in previous studies [30, 33-36]. These associations were not revealed in our 210 patients. We expect that this is due to a relatively low power, caused by the relatively low number of cases experiencing depressive symptoms. This is a main limitation of our study. Besides, variations in study design and participants' demographic characteristics might also be the reasons for the discrepancy.

In the final stepwise logistic regression we found that female gender was an independent risk factor for depressive symptoms, which was in line with previous studies [37, 38]. Sun et al. [39] found an association between being woman and depressive symptoms. This sex difference could be due to lower physical activity lifestyle and being more emotional than men.

Besides being female, hypertension was also an independent risk factor for depressive symptoms among T2DMrelated CKD patients by stepwise logistic regression. Based on the previous studies [40,41], hypertension has been demonstrated to be an independent risk factor of depressive symptoms among patients with T2DM due to increased risk of serious cardiovascular disease complications, reduced quality of life, and poor prognosis.

Additionally, the stepwise logistic regression analysis also indicated that the T2DM-related CKD progression was significantly associated with depressive symptoms. CKD with type 2 diabetic patients were reported to experience symptoms like inability to sleep, depression, and lack of energy when they perceived gradual worsening of their symptoms. As the disease progresses, the decline of the renal function eventually resulted in the outcomes of dialysis. Above feelings will be aggravated gradually [42]. Similarly, our results also showed that the prevalence of depressive symptoms was gradually increased along with the progress of disease. In stages I-V, depression was $8.1 \%, 24.4 \%, 20.0 \%, 37.5 \%$, and $56.3 \%$, respectively. About sixty percent of ESRD symptoms would be complicated by depressive symptoms. Young et al. [4] suggested further testing of targeted depression interventions should be considered in this population, for the reason that major depression at baseline was associated with a 3fold greater risk of mortality among Stage V CKD diabetic patients.

At the end, there are several limitations in our research that should be addressed. First, our sample was selected from one hospital in China for convenience. The study cannot be considered as representative of the T2DM-related CKD population in China. Second, we used self-reported and closedended questionnaires. Third, the number of complications and treatments of ESRD were not considered. Fourth, the sample size in this study is relatively smaller than some other studies.

In conclusion, T2DM-related CKD patients showed a higher predisposition to depression. Medical staff should pay more attention to the psychological issues when T2DM patients were involved in the treatment of CKD, especially for female patients in late stage complicated with hypertension.

\section{Competing Interests}

The authors declare that they have no competing financial interests.

\section{Authors' Contributions}

Weiqun Weng and Xueqin Wang designed the study. Xu Wang and Biyu Shen acquired and analyzed the data. Xun Zhuang interpreted the data. Xu Wang wrote the paper. All authors reviewed the manuscript. 


\section{Acknowledgments}

This work was supported by the Nantong Science and Technology Board (MS32015022).

\section{References}

[1] M. B. Duran-Salgado and A. F. Rubio-Guerra, "Diabetic nephropathy and inflammation," World Journal of Diabetes, vol. 5, no. 3, pp. 393-398, 2014.

[2] A. T. Joyce, J. M. Iacoviello, S. Nag et al., "End-stage renal disease-associated managed care costs among patients with and without diabetes," Diabetes Care, vol. 27, no. 12, pp. 2829-2835, 2004.

[3] S. S. Hedayati, S. C. Grambow, L. A. Szczech, K. M. Stechuchak, A. S. Allen, and H. B. Bosworth, "Physician-diagnosed depression as a correlate of hospitalizations in patients receiving longterm hemodialysis," American Journal of Kidney Diseases, vol. 46, no. 4, pp. 642-649, 2005.

[4] B. A. Young, W. J. Katon, M. Von Korff et al., "Racial and ethnic differences in microalbuminuria prevalence in a diabetes population: the pathways study," Journal of the American Society of Nephrology, vol. 16, no. 1, pp. 219-228, 2005.

[5] C. E. Lloyd, N. Sartorius, L. C. Cimino et al., "The INTERPRETDD study of diabetes and depression: a protocol," Diabetic Medicine, vol. 32, no. 7, pp. 925-934, 2015.

[6] M. K. Kramer, A. M. Kriska, E. M. Venditti et al., "Translating the Diabetes Prevention Program. a comprehensive model for prevention training and program delivery," American Journal of Preventive Medicine, vol. 37, no. 6, pp. 505-511, 2009.

[7] S. Moussavi, S. Chatterji, E. Verdes, A. Tandon, V. Patel, and B. Ustun, "Depression, chronic diseases, and decrements in health: results from the World Health Surveys," Lancet, vol. 370, no. 9590, pp. 851-858, 2007.

[8] E. H. B. Lin, C. M. Rutter, W. Katon et al., "Depression and advanced complications of diabetes: a prospective cohort study," Diabetes Care, vol. 33, no. 2, pp. 264-269, 2010.

[9] M. De Groot, R. Anderson, K. E. Freedland, R. E. Clouse, and P. J. Lustman, "Association of depression and diabetes complications: a meta-analysis," Psychosomatic Medicine, vol. 63, no. 4, pp. 619-630, 2001.

[10] W. J. Katon, C. Rutter, G. Simon et al., "The association of comorbid depression with mortality in patients with type 2 diabetes," Diabetes Care, vol. 28, no. 11, pp. 2668-2672, 2005.

[11] L. E. Egede, P. J. Nietert, and D. Zheng, "Depression and allcause and coronary heart disease mortality among adults with and without diabetes," Diabetes Care, vol. 28, no. 6, pp. 13391345, 2005.

[12] E. H. B. Lin, S. R. Heckbert, C. M. Rutter et al., "Depression and increased mortality in diabetes: unexpected causes of death," Annals of Family Medicine, vol. 7, no. 5, pp. 414-421, 2009.

[13] M. K. Yu, N. S. Weiss, X. Ding, W. J. Katon, X.-H. Zhou, and B. A. Young, "Associations between depressive symptoms and incident ESRD in a diabetic cohort," Clinical Journal of the American Society of Nephrology, vol. 9, no. 5, pp. 920-928, 2014.

[14] S. Ali, M. A. Stone, J. L. Peters, M. J. Davies, and K. Khunti, "The prevalence of co-morbid depression in adults with Type 2 diabetes: a systematic review and meta-analysis," Diabetic Medicine, vol. 23, no. 11, pp. 1165-1173, 2006.

[15] K. D. Barnard, T. C. Skinner, and R. Peveler, "The prevalence of co-morbid depression in adults with Type 1 diabetes: systematic literature review," Diabetic Medicine, vol. 23, no. 4, pp. 445-448, 2006.

[16] N. A. Hashim, S. Ariaratnam, M. R. Salleh, M. A. Said, and A. H. Sulaiman, "Depression and associated factors in patients with type 2 diabetes mellitus," East Asian Archives of Psychiatry, vol. 26, no. 2, pp. 77-82, 2016.

[17] B. Mezuk, W. W. Eaton, S. H. Golden, and Y. Ding, "The influence of educational attainment on depression and risk of type 2 diabetes," American Journal of Public Health, vol. 98, no. 8, pp. 1480-1485, 2008.

[18] M. K. Yu, W. Katon, and B. A. Young, "Diabetes self-care, major depression, and chronic kidney disease in an outpatient diabetic population," Nephron. Clinical Practice, vol. 124, no. 1-2, pp. 106112, 2013.

[19] M. J. Fischer, P. L. Kimmel, T. Greene et al., "Sociodemographic factors contribute to the depressive affect among African Americans with chronic kidney disease," Kidney International, vol. 77, no. 11, pp. 1010-1019, 2010.

[20] W. J. Kop, S. L. Seliger, J. C. Fink et al., "Longitudinal association of depressive symptoms with rapid kidney function decline and adverse clinical renal disease outcomes," Clinical Journal of the American Society of Nephrology, vol. 6, no. 4, pp. 834-844, 2011.

[21] N. K. Foundation, "K/DOQI clinical practice guidelines for chronic kidney disease: evaluation, classification, and stratification," American Journal of Kidney Diseases, vol. 39, supplement 1, no. 2, pp. S1-266, 2002.

[22] KDOQI, "KDOQI clinical practice guidelines and clinical practice recommendations for diabetes and chronic kidney disease," American Journal of Kidney Diseases, vol. 49, no. 2, supplement 2, pp. S12-S154, 2007.

[23] C. E. Mogensen, "Microalbuminuria, blood pressure and diabetic renal disease: origin and development of ideas," Diabetologia, vol. 42, no. 3, pp. 263-285, 1999.

[24] X. Liu, X. Qiu, C. Shi et al., "Modified glomerular filtration rate-estimating equations developed in asiatic population for Chinese patients with type 2 diabetes," International Journal of Endocrinology, vol. 2014, Article ID 521071, 9 pages, 2014.

[25] Q. Xu, X. Li, B. Gao et al., "Comparative performance of four equations estimating glomerular filtration rate in adult Chinese diabetics," Journal of Endocrinological Investigation, vol. 36, no. 5, pp. 293-297, 2013.

[26] Y. Ma, L. Zuo, J. H. Chen et al., "Modified glomerular filtration rate estimating equation for Chinese patients with chronic kidney disease," Journal of the American Society of Nephrology, vol. 17, no. 10, pp. 2937-2944, 2006.

[27] A. S. Zigmond and R. P. Snaith, "The hospital anxiety and depression scale," Acta Psychiatrica Scandinavica, vol. 67, no. 6, pp. 361-370, 1983.

[28] C. Brennan, A. Worrall-Davies, D. McMillan, S. Gilbody, and A. House, "The Hospital Anxiety and Depression Scale: a diagnostic meta-analysis of case-finding ability," Journal of Psychosomatic Research, vol. 69, no. 4, pp. 371-378, 2010.

[29] S. Wang, W. Fan, W. Yu et al., "Analysis on reliability and validity of SF-36 scale in urban residents," Zhonghua Liu Xing Bing Xue Za Zhi, vol. 37, no. 3, pp. 344-347, 2016.

[30] M. Papelbaum, R. O. Moreira, W. Coutinho et al., "Depression, glycemic control and type 2 diabetes," Diabetology \& Metabolic Syndrome, vol. 3, no. 1, article 26, 2011.

[31] S. I. Zuberi, E. U. Syed, and J. A. Bhatti, "Association of depression with treatment outcomes in Type 2 Diabetes Mellitus: A cross-sectional study from Karachi, Pakistan," BMC Psychiatry, vol. 11, article no. 27, 2011. 
[32] C. Tovilla-Zárate, I. Juárez-Rojop, Y. Peralta Jimenez et al., "Prevalence of anxiety and depression among outpatients with type 2 diabetes in the Mexican population," PLOS ONE, vol. 7, no. 5, Article ID e36887, 2012.

[33] A. K. Khuwaja, S. Lalani, R. Dhanani, I. S. Azam, G. Rafique, and F. White, "Anxiety and depression among outpatients with type 2 diabetes: a multi-centre study of prevalence and associated factors," Diabetology \& Metabolic Syndrome, vol. 2, no. 1, article 72, 2010.

[34] J. Labad, J. F. Price, M. W. J. Strachan et al., "Symptoms of depression but not anxiety are associated with central obesity and cardiovascular disease in people with type 2 diabetes: the Edinburgh Type 2 Diabetes Study," Diabetologia, vol. 53, no. 3, pp. 467-471, 2010.

[35] T. D. Habtewold, S. M. Alemu, and Y. G. Haile, "Sociodemographic, clinical, and psychosocial factors associated with depression among type 2 diabetic outpatients in Black Lion General Specialized Hospital, Addis Ababa, Ethiopia: a crosssectional study," BMC Psychiatry, vol. 16, no. 1, article no. 103, 2016.

[36] G. Kaur, G. H. Tee, S. Ariaratnam, A. S. Krishnapillai, and K. China, "Depression, anxiety and stress symptoms among diabetics in Malaysia: a cross sectional study in an urban primary care setting," BMC Family Practice, vol. 14, article 69, 2013.

[37] X. Zhou, B. Bi, L. Zheng et al., "The prevalence and risk factors for depression symptoms in a rural Chinese sample population," PLoS ONE, vol. 9, no. 6, Article ID e99692, 2014.

[38] R. Rajput, P. Gehlawat, D. Gehlan, R. Gupta, and M. Rajput, "Prevalence and predictors of depression and anxiety in patients of diabetes mellitus in a tertiary care center," Indian Journal of Endocrinology and Metabolism, vol. 20, no. 6, pp. 746-751, 2016.

[39] N. Sun, P. Lou, Y. Shang et al., "Prevalence and determinants of depressive and anxiety symptoms in adults with type 2 diabetes in China: a cross-sectional study," BMJ Open, vol. 6, no. 8, 2016.

[40] K. Ganasegeran, P. Renganathan, R. A. Manaf, and S. A. R. AlDubai, "Factors associated with anxiety and depression among type 2 diabetes outpatients in Malaysia: a descriptive crosssectional single-centre study," BMJ Open, vol. 4, no. 4, Article ID e004794, 2014.

[41] M. Palizgir, M. Bakhtiari, and A. Esteghamati, "Association of depression and anxiety with diabetes mellitus type 2 concerning some sociological factors," Iranian Red Crescent Medical Journal, vol. 15, no. 8, pp. 644-648, 2013.

[42] I.-C. Yu and Y.-F. Tsai, "From silence to storm-patient illness trajectory from diabetes diagnosis to haemodialysis in Taiwan: a qualitative study of patients' perceptions," Journal of Advanced Nursing, vol. 69, no. 9, pp. 1943-1952, 2013. 


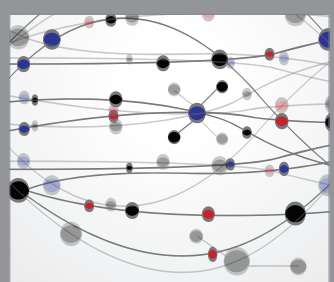

The Scientific World Journal
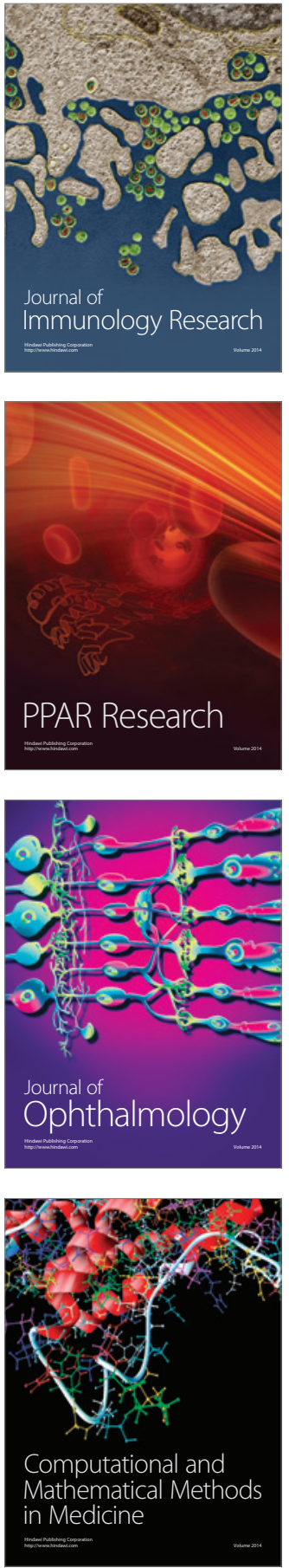

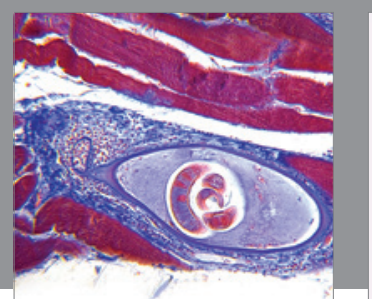

Gastroenterology Research and Practice
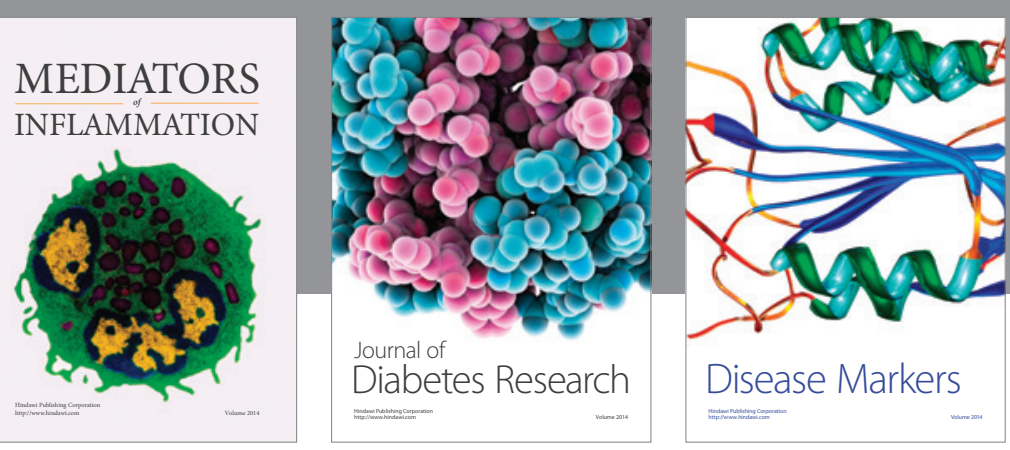

Disease Markers

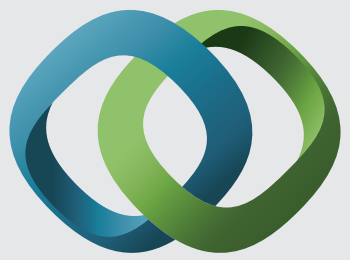

\section{Hindawi}

Submit your manuscripts at

https://www.hindawi.com
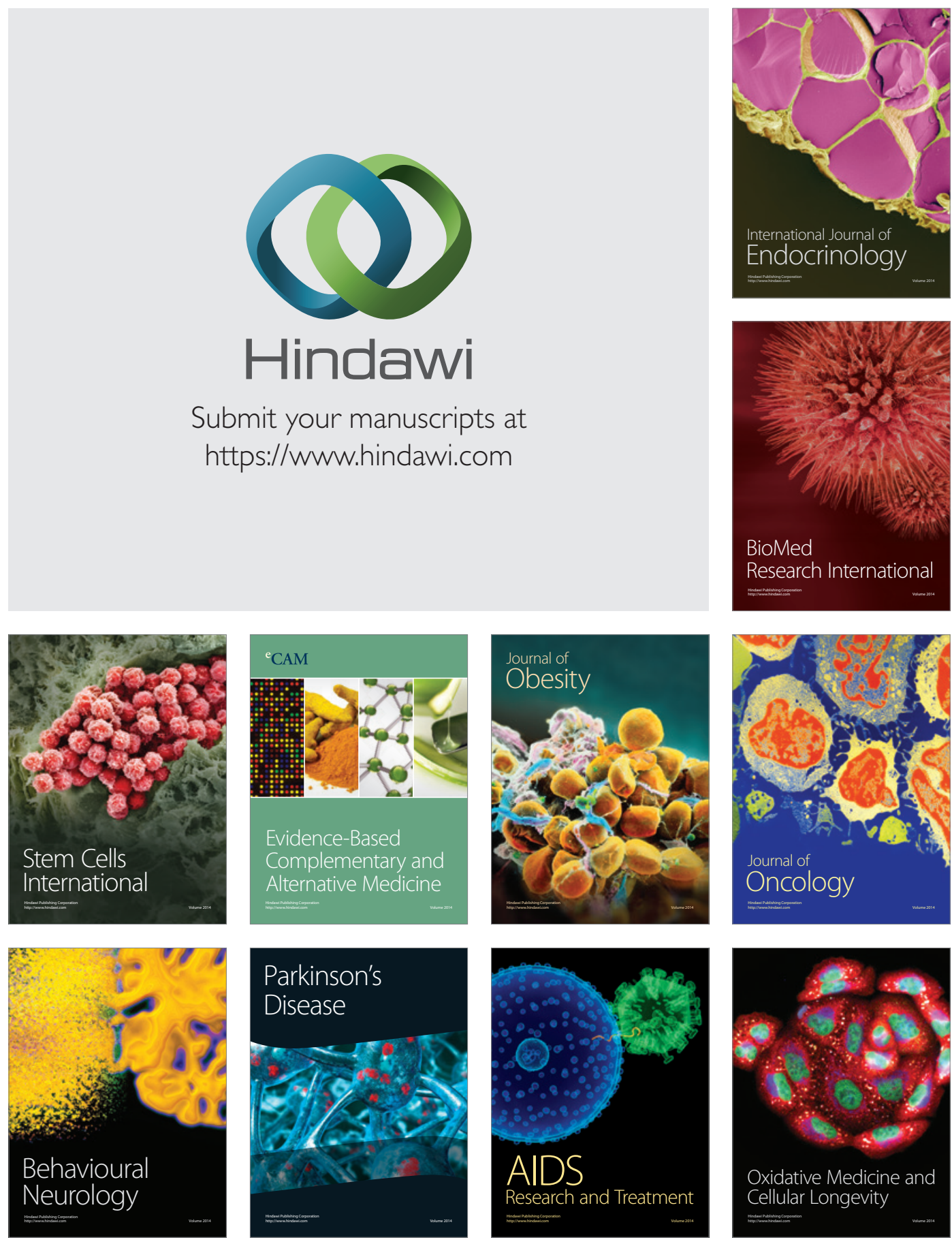